\title{
The clinicopathologic features and response to treatment of patients with Nonhodgkin Lymphoma: A single-center experiment in Turkey
}

\author{
Rahsan Yildirim ${ }^{1}$, Gulden Sincan ${ }^{2}$
}

\begin{abstract}
Objective: We aimed to compare laboratory features, histopathological types, response to treatment of patients with non hodgkin lymphoma in our department and other regions.

Methods: A total of 80 patients nonhodgkin lymphoma were evaluated. Because we had only 80 patients with complete data, we used $T$ test for comparison of groups. We evaluated the parameters affecting surveillance with cox regression analysis.

Results: The most common histological types of nonhodgkins lymphoma was diffuse large b cell lymphoma (n: 63, 78.75\%). Thirty-nine percent of all patients had anemia, 32\% had hypoalbunemia, $71.25 \%$ had elevated serum LDH, 32.5\% had elevated serum B2 microglobulin value. Advanced age, the presence of bulky disease, elevated Ki-67 level, IPI score, refractory to first line treatment were found to be correlated with shorter survival time. We treated $77(96.25 \%)$ patients with doxorubicin containing regimen. Complete and partial remission rates of first line treatment were $77.5 \%$ and $10 \%$, respectively. Seven $(8.75 \%)$ patients died because of disease progression and 1 (1.25\%) patient died due to sepsis.

Conclusion: The frequency of lymphoma subtypes, clinical characteristics, treatment outcomes and survival rate vary from region to region. Therefore it is important to determine dissimilarity of these parameters for improve of survey.
\end{abstract}

KEYWORDS: Nonhodgkin lymphoma, Laboratory findings, Response to treatment.

How to cite this:

doi: https://doi.org/10.12669/pjms.35.1.415

Yildirim $R$, Sincan $G$. The clinicopathologic features and response to treatment of patients with Nonhodgkin Lymphoma; $A$ singlecenter experiment in Turkey. Pak J Med Sci. 2019;35(1):82-85. doi: https://doi.org/10.12669/pjms.35.1.415

This is an Open Access article distributed under the terms of the Creative Commons Attribution License (http://creativecommons.org/licenses/by/3.0), which permits unrestricted use, distribution, and reproduction in any medium, provided the original work is properly cited.

1. Dr. Rahsan Yildirim,

Department of Hematology,

Medical School,

Ataturk University,

Erzurum, Turkey

2. Dr. Gulden Sincan,

Department of Hematology,

Erzurum Regional Training and Research Hospital,

Erzurum, Turkey.

Correspondence:

Dr. Gulden Sincan,

Department of Hematology,

Erzurum Regional Training and Research Hospital,

Erzurum, Turkey.

E-mail: guldensincan@gmail.com

* Received for Publication:

March 18, 2018

* Revision Received:

October 29, 2018

* Accepted for Publication:
November 2, 2018

\section{INTRODUCTION}

Non-hodgkin lymphoma's (NHL) are a heterogeneous group of lymphoproliferative malignancies. ${ }^{1}$ Almost $85 \%$ of NHLs are of B-cell origin; only $15 \%$ are derived from $\mathrm{T} / \mathrm{NK}$ cells. Based on the World Health Organization (WHO) classification, the two most common NHL's subtypes are diffuse large B-cell lymphoma (DLBCL), occurring in $31 \%$ of patients, and follicular lymphoma (FL), occurring in $22 \%$ patients.

The prognosis and type of treatment of NHL depend on the histological subtype, disease stage and associated comorbid conditions. Chemotherapy and radiotherapy are the two principal forms of treatment. Autologous and allogenic stem cell transplantations and a watch-and-wait strategy are 
also used to treatment some NHL subtypes. CAR T cells, blinatumumab, immune checkpoint inhibitors are novel drugs used for treatment of NHL.

\section{METHODS}

We examined 80 patients with NHL retrospectively. Approval of the Ataturk University Ethics Committee was obtained for the study. Excision biopsy was performed for diagnosis in most of the cases. A diagnosis of NHL was established according to WHO criteria. Complete blood count, albumine, lactate dehydrogenase, uric acid, ferritin, beta 2 (B2) microglobuline levels of all participants were determined from patients records. B symptoms were defined as $>38^{\circ} \mathrm{C}$ fever, night sweating, $>10 \%$ weight loss in the last six months. Ann Arbor classification was used for staging of patients.Stage of disease, presence of bulky disease, extranodal involvement, performance status of Eastern Cooperative Oncology Group (ECOG), score of international prognostic index (IPI), type of treatment applied and response to treatment of all patients were determined. The evaluation of treatment response was made in accordance with WHO criteria. Overall survival (OS) was defined as time from start of treatment to either death from any reason. All statistical analyses were performed using SPSS version 20.0. Numerical data were expressed as number and percentage. We used $\mathrm{T}$ test for comparison of groups. Cox regression analysis was used for survey assessment. $\mathrm{P}<0.05$ was considered statistically significant.

\section{RESULTS}

In this study, 80 patients with NHL were evaluated. Thirty three patients were females and 47 males (male/female ratio: $47 / 33=1.4$ ), and the median age was $57.6 \pm 16.6$ years (range: 1887 years). There wasn't statistically significant difference in age between male and female group ( $p$ value: 0.01 ). B-cell and T-cell originated NHL were identified in $76(95 \%)$ patients and in $4(5 \%)$

Table-I: Distribution of histological subtypes in patients with lymphoma.

\begin{tabular}{lcc}
\hline Subtypes of NHL & No. of Cases & Percent (\%) \\
\hline Diffuse Large B Cell Lymphoma & 63 & 78.75 \\
Peripheral T Cell Lymphoma & 4 & 5 \\
Follicular Lymphoma & 4 & 5 \\
Mantle Cell Lymphoma & 3 & 3.75 \\
Burkitt Lymphoma & 2 & 2.5 \\
Marginal Zone Lymphoma & 2 & 2.5 \\
Small Lymphocyctic Lymhoma & 2 & 2.5 \\
\hline
\end{tabular}

patients, respectively. DLBCL was the most commonly histopathologic type $(78.75 \%)$. The most common subtype of T-cell lymphomas was the peripheral $t$ cell lymphoma (NOS) with 3 patients. Histopathological classification of the all patients is showed in Table-I. Comorbid diseases are specified in Table-II.

According to Ann Arbor Staging System, 7.5\% (n:6) of all patients had Stage I, 31.25\% (n:25) had Stage II, $16.25 \%$ (n: 23) had stage III, 32.5\% (n: 26) had Stage IV. B symptoms were seen in 45 (56.25\%) patients. B symptoms were seen more common in patients with $\geq 60$ ages rather than in patients with $<60$ ages $(p<0.01)$. ECOG performance status was stage 1 in $11(13.75 \%)$ patients, was stage 2 in 37 $(46.25 \%)$ patients, was stage 3 in $26(32.5 \%)$ patients and was stage $4(7.5 \%)$ in 6 patients. The presence B symptoms, elevated Ki-67 level, advanced stage, extra lymphatic involvement were associated with high ECOG score, significantly. IPI score was 0 in 1 (\%) patients, was 1 in $8(\%), 2$ in $16(\%), 3$ in 32 $(\%), 4$ in $19(\%)$, and 5 in $4(\%)$ patients at the time of diagnosis. $12(15 \%)$ patients had bulky mass. Bulky disease was seen more common in patients who had comorbid disease $(p<0.02)$. Extranodal involvement was determined in $36(45 \%)$ cases. The most frequently sites of extranodal involvement were: gastrointestinal system (n:12, 15\%), lung (n:7, $8.75 \%)$, spleen (n:6, 7.5\%), bone (n:5, 6.25\%), liver $(\mathrm{n}: 4,5 \%)$, renal $(\mathrm{n}: 2,2.5 \%)$.

Laboratory findings were as follows; the levels of hemoglobine was 11.6 \pm 2.6 (min:6 max.16.1), white blood cell (WBC) was 27095 \pm 12620 (min:11000, max:27050), uric acid was 7.5 \pm 2.2 (min:3.7, max:12.4), 12 microglobuline was $4.6 \pm 3$ (min:2, max.16), ferritin was $385.5 \pm 668.9$ (min: 8 , max.4400), Ki-67 76 \pm 14.1 (min:30, max:95). Thirty nine patients

Table-II: Comorbid disease associated with Non-Hodgkin Lymphoma.

\begin{tabular}{lcc}
\hline Disease & No. of Patients & Percent (\%) \\
\hline Hypertension & 10 & 12.5 \\
Diabetes Mellitus & 5 & 6.2 \\
Goiter & 5 & 6.2 \\
Chronic Obstructive & 3 & 3.8 \\
$\quad$ Pulmonary Disease & & \\
Rheumatoid arthritis & 2 & 2.5 \\
Benign Prostatic Hyperplasia & 2 & 2.5 \\
Coronary Artery Disease & 2 & 2.5 \\
Chronic hepatitis & 1 & 1.25 \\
Hyperlipidemia & 1 & 1.25 \\
Gastric Cancer & 1 & 1.25 \\
Invasive Ductal Cancer & 1 & 1.25 \\
\hline
\end{tabular}


had anemia, 11 had leucostosis, 57 had elevated LDH level, 32 had hypoalbunemia, 26 had elevated B2 microglobulin, 32 had elevated uric acid level.

We treated $71(88.75 \%)$ patients with R-CHOP, 6 $(7.5 \%)$ patients with CHOP, $2(2.5 \%)$ patients with R-Hypercvad and 1 (1.25\%) patient with R-Gemox treatment protocols for first line treatment. Sixty two $(77.5 \%)$ patients achieved a complete response, $8(10 \%)$ patients had a partial response with first line therapy. Four (5\%) patients had stable disease and 6 $(7.5 \%)$ patients had progressive disease. The median time to first relapse after the first line treatment was 26 months. In second-line treatment, R-ICE regimen was used in $18(22.5 \%)$ patients, R-DHAP regimen was used in $10(12.5 \%)$ patients although each of ICE regimen and DHAP regimen were used only one patient. Sixteen $(20 \%)$ patients were achieved to complete remission with second line treatment. Each of partial remission and progressive disease were in $7(8.8 \%)$ patients. Eight $(10 \%)$ patients were treated with autologous bone marrow transplantation after salvage chemotherapy. We treated 3 patients with ASHAP regimen in third line treatment. seven $(8.75 \%)$ patients died because of disease progression and one $(1.25 \%)$ patient died due to sepsis. Mean survey was associated with advanced age, bulky disease, elevated ki-67 level, IPI score, response to treatment first line treatment. Mean survey time was 27.5 \pm 17.3 (min:1, max.60) months.

\section{DISCUSSION}

NHL is the 6th most common type of cancer. ${ }^{2}$ The frequency of NHL subtypes varies according to geographical regions. ${ }^{3}$ Eighty- eighty five percent of NHLs are derivated from Bcells, while 15-20\% are from T-cells in USA. In our study, B-cell origin lymphomas were found as $95 \%$, and T-cell origin lymphomas as $5 \%$. In our country, $\mathrm{T}$ cell originated lymphoma is very rare. The most common histological subtype of NHL is DLBCL with a frequency of $31 \%$. DLBCL is very common $(78.75 \%)$ in our country compared to USA, Asian and European countries. FL is rare in Chine and Middle East while it is more common in USA. We found that follicular lymphoma incidence was $5 \%$ and it was rare in our country. This may be explained by follicular lymphoma was relatively less because of DLBCL had very higher incidence in our country.

NHL is more common in people aged over 65 year in U.S.A. The median age was 57.6 in our study and NHL was seen at an earlier age in our country rather than U.S.A. Isikdogan et al reported that the median age was 43 years in patients living in the southeast Turkey. ${ }^{4}$ In addition, the average age of at diagnosis was 44 years in one study that was made by Barista et al. in central Turkey. ${ }^{5}$ The median age of our patients was higher than the patients in southern and central Turkey. The incidence of lymphoma is higher in men than in women. In U.S.A and Europa, male dominancy rates is different. ${ }^{6}$ Male/female ratio was 1.4 in our study according to literature. It was reported that NHL was seen in men at an earlier age. But in our study, it wasn't significantly difference between men and women in terms of age ( $\mathrm{p}$ value: 0.06 )

The current staging system for NHL in adults is known as the Lugano classification, which is based on the older Ann Arbor System.7 Most patients with non-Hodgkin's lymphomas had advanced stage. ${ }^{8}$ In our study; stage 3 and 4 NHL was found in 49 patients according to literature. The effects of the presence of B-symptoms on the survival rate have been reported in a study by Maksymiuk et al. ${ }^{9}$ In our study, we didn't find a relationship between the presence of B symptom and survey time (p: 0.06). The ECOG scale $\geq 2$ was an adverse prognostic factor. ${ }^{10}$ We didn't determine the relationship with ECOG score and survey time (p: 0.06).

The extranodal involvement was observed in 20$30 \%$ of patients with NHL. ${ }^{10}$ In a study performed by Tabakan et al. in Turkey, extranodal involvement was detected in $43.9 \%{ }^{11}$ The extranodal involvement was found as $44 \%$ in the study by Isikdogan. ${ }^{4} \mathrm{We}$ found an extranodal involvement ratio of $45 \%$ according to the studies that were made in Turkey. The most common site of extranodal involvement was the gastrointestinal system with $15 \%$ in our study. The incidence of gastric involvement was $66 \%$ in a study in Ankara by made Alican et al. ${ }^{12}$ We found that the gastric involvement incidence was $12.5 \%$. A correlation between survey time and extranodal organ involvement has not been reported in the literature. ${ }^{13}$ We didn't detect that the effect of extranodal involvement on survey time (p:0.07).

In the literature, lower serum albumin levels adversely effected the survival time. ${ }^{14}$ In our study a statistically significant difference was not found between serum albumin level and survival time (p:0.06). It was detected that anemia was associated with poorer $\mathrm{CR}$ rate. ${ }^{10} \mathrm{We}$ didn't find any correlation with anemia and survey time (p: 0.07).

The nuclear proliferation antigen $\mathrm{Ki}-67$ is a marker of tumor cell proliferation rate. Higher Ki-67 level was associated with poorer survival. ${ }^{15}$ 
Miller and et al evaluated that the effect of high Ki 67 (Ki-67 $\geq 80 \%$ ) on survive time. They didn't find significantly relationship between Ki-67 level and survey time. ${ }^{16}$ We considered $>60 \% \mathrm{Ki}-67$ value as high. We detected that the mean survey time was shorter in the patients that had high Ki-67 value (p: 0.01).

Patients with NHL who is treated with doxorubicine containing regimen have high complete remission rate. Rate of complete response to treatment is around $60-80 \%$ in NHL. Five year survival rate is over $55 \%$ and it was reported as $54.6 \%$ in European study. ${ }^{17}$ Five-year survival rate was reported to range $50-60 \%$ in Scandinavian countries..$^{18}$ In our study, 5-year survival rate was $45 \%$ and it was lower in our country than Europa.

There were 63 patients with DLBCL in our study and the rate of response to first line treatment was $71.4 \%$. It was reported that the remission rate was $65-70 \%$ with anthracycline-based regimens plus anti-CD20 antibody in patients with DLBCL. ${ }^{19}$ The response to first line treatment in patients with DLBCL was according to literature.

\section{CONCLUSION}

The frequency of NHL subtypes varies from region to region. There are differences between regions in terms of clinicopathological features and response to treatment. Therefore it is important to identify these differences for management of patients.

\section{Source of funds: None.}

\section{Conflicts of interest: None.}

\section{REFERENCES}

1. Armitage JO, Weisenburger DD. New approach to classifying non-Hodgkin's lymphomas: Clinical features of the major histologic subtypes. Non-Hodgkin's Lymphoma Classification Project. J Clin Oncol. 1998:16(8):2780-2795. doi: 10.1200/JCO.1998.16.8.2780

2. Siegel RL, Miller KD, Jemal A. Cancer Statistics. Cancer J Clin. 2015;65:5-29 doi: 10.12691/jcrt-4-2-3

3. Aisenberg AC. Coherent view of non-Hodgkin's lymphoma. J Clin Oncol. 1995;13:2656-2675. doi: 10.1200/ JCO.1995.13.10.2656

4. Isikdogan A, Ayyildiz O, Buyukcelik A, Arslan A, Tiftik $\mathrm{N}$, Buyukbayram $\mathrm{H}$, et al Non-Hodgkin's lymphoma in southeast Turkey: clinicopathologic features of 490 cases. Ann Hematol. 2004;83(5):265-269. doi: 10.1007/s00277-0030812-0

5. Barista I, Tekuzman G, Firat D, Baltali E, Kansu E, Kars A, et al. Non-Hodgkin's Lymphomas in Turkey: Eighteen Years' Experience at the Hacettepe University. Jpn J Cancer Res. 1994;85:1200-1207. doi: 10.1111/j.13497006.1994.tb02930.x.
6. Lee SS, Cho KJ, Kim CG, Kang YK. Clinicopathological analysis of 501 non-Hodgkin's lymphomas in Korea according to the Revised European-American Classification of lymphoid neoplasms. Histopathology. 1999;35(4):345354. doi: 10.1046/j.1365-2559.1999.00721.x.

7. Cheson, BD, Fisher RI, Barrington SF, Cavalli F, Schwartz LH, Zucca E, et al. Recommendations for initial evaluation, staging, and response assessment of Hodgkin and nonHodgkin lymphoma: The Lugano classification. J Clin Oncol. 2014;32(27):3059-3067. doi: 10.1200/JCO.2013.54.8800

8. Ansell SM. Non-Hodgkin Lymphoma: Diagnosis and Treatment. Mayo Clin Proc. 2015;90(8):1152-1163. doi: 10.1016/j.mayocp.2015.04.025.

9. Maksymiuk AW, Bratvold JS, Ezzat W, Tan LK, Skinnider LF. Non-Hodgkin's lymphoma in Saskatchewan. A review of 10 years experience. Cancer. 1994;73(3):711-719. doi: 10.1002/1097-0142(19940201.

10. Nicolaides C, Fountzilas G, Zoumbos N, Skarlos D, Kosmidis P, Pectasides D, et al. Diffuse large cell lymphomas: identification of prognostic factors and validation of the International Non Hodgkin's Lymphoma Prognostic Index. Oncology. 1998;55(5):405-415. doi: 10.1159/000011886

11. Tabakan F, Nayır E, Arican A. Clinical and pathological evaluation of histopathological subtypes in patients with non-Hodgkin's Lymphoma. Eur Res J. 2016;2(1):52-61. doi: 10.18621/eurj. 2016.2.1.52

12. Arican A, Dinçol D, Akbulut H, Onur H, Demirkazik A, Cay $\mathrm{F}$, et al. Clinicopathologic features and prognostic factors of primary extranodal nonHodgkin's lymphomas in Turkey. Am J Clin Oncol. 1999;22:587-592.

13. Mishra P, Das S, Kar R, Jacob SE, Basu D. Primary extranodal non-Hodgkin lymphoma: A 3-year record-based descriptive study from a tertiary care center in Southern India. Indian J Pathol Microbiol. 2015;58(3):296-300. doi: 10.4103/03774929.162834.

14. Shipp MA. Prognostic factors in aggressive nonHodgkin's lymphoma: who has "high-risk" disease. Blood. 1994;83(5):1165-1173.

15. Slymen DJ, Miller TP, Lippman SM, Spier CM, Kerrigan DP, Rybski JA, et al. Immunobiologic factors predictive of clinical outcome in diffuse large-cell lymphoma. J Clin Oncol. 1990;8:986-993. doi: 10.1200/JCO.1990.8.6.986.

16. Miller TP, Grogan TM, Dahlberg S, Spier CM, Braziel RM, Banks PM, et al. Prognostic significance of the Ki67-associated proliferative antigen in aggressive nonHodgkin's lymphomas: a prospective Southwest Oncology Group trial. Blood. 1994;83:1460-1466.

17. Verdecchia A, Francisci S, Brenner H, Gatta G, Micheli A, Mangone L, et al. Recent cancer survival in Europe: A 200002 period analysis of EUROCARE-4 data. Lancet Oncol. 2007;8(9):784-796. doi:10.1016/S1470-2045(07)70246-2

18. Hakulinen T, Tryggvadottir L, Gislum M, Storm HH, Bray $\mathrm{F}$, Klint A, et al. Trends in the survival of patients diagnosed with malignant neoplasms of lymphoid, haematopoietic, and related tissue in the Nordic countries 1964-2003 followed up to the end of 2006. Acta Oncol. 2010;49(5):694712. doi: $10.3109 / 02841860903575307$.

19. National Comprehensive Cancer Network guidelines, version 2.2016. Diffuse large B-cell lymphoma. NCCN, 2016.

\section{Authors' Contributions:}

GS: Designed and did statistical analysis, manuscript writing

RY: Did data collection. 